\title{
Application of FISH Technique in Evaluation of Equivocal Cases of HER2/neu in Breast Carcinoma
}

\author{
Saja Faisal Jaafar* , Ekhlas Ahmed Ali** Nazar Mohammed Jawhar** \\ ${ }^{*}$ Postgraduate Student , Department of Pathology, College of Medicine , University of Mosul , \\ ${ }^{\star \star}$ Department of Pathology, College of Medicine, University of Mosul , ${ }^{* \star \star}$ Department of Pathology, \\ College of Medicine, University of Nineveh, Mosul, Iraq \\ Correspondence: sajafaisal06@gmail.com
}

(Ann Coll Med Mosul 2020; 42 (2):133-140).

Received: $18^{\text {th }}$ Oct. 2020; Accepted: $6^{\text {th }}$ Dec. 2020.

\begin{abstract}
Background: Breast cancer in Iraqi females is one of the extreme popular malignant tumors. It represents the third of registered female cancers. Management and outcome of breast cancer are affected by variables such as tumor size and grade, as well as histologic type, HER2/neu status of the tumor and hormone receptor status. HER2/neu (or erbB-2) is a proto-oncogene found on chromosome 17, that is overexpressed and/or amplified in $15 \%$ to $25 \%$ of invasive breast carcinomas and is connected to worse clinical outcome. Patients with HER2/neu positive breast carcinoma have showed a good response to targeted therapy (Herceptin) that improving the prognosis.

Objectives: To assess the immunohistochemical overexpression of HER2/neu in breast carcinoma, to detect the frequency of amplified HER2/neu by FISH on immunohistochemically equivocal cases, and to correlate HER2 overexpression \& or amplification with various clinicopathological parameters.

Patients and Method: A total of hundred breast carcinoma patients at different ages were included in this retrospective and prospective case series study design. Formalin fixed paraffin embedded blocks were collected from different private labs in Mosul, between 1st November 2019 to 1 st April 2020. FISH technique was performed on 25 equivocal cases of HER2/neu tested by immunohistochemistry technique using Leica Kreatech ${ }^{\text {TM }}$ FISH Dual Probe (Red/Green).

Results: Among a total of 100 patients with mean age was (52) years old diagnosed as breast carcinoma via histopathological findings, $58 \%$ were tested negative for HER2/neu, $17 \%$ positives for HER2/neu, and $25 \%$ were equivocal by Immunohistochemistry. However, FISH method is conducted for those patients indicated as equivocal at immunohistochemistry and has identified $7(28 \%)$ positive cases and $18(72 \%)$ negative cases. The association between HER2/neu and the grade of the tumor was statistically considerable ( $P$ value $=0.03$ ). Furthermore, the analysis indicated that the HER2/neu was not statistically related with histological type of the tumor and age of the patients $(P$ value $=0.35, P$ value $=0.75$, respectively). In this study, HER2/neu was statistically inversely associated with both ER and PR receptors ( $P$ value $=0.03, P$ value $=0.05$, respectively).

Conclusion: HER2/neu is overexpressed by immunohistochemistry in 17\%. HER2/neu is amplified by FISH (in equivocal cases) in $28 \%$. HER2/neu is statistically significant correlation with tumor grade, and is in inverse statistically significant correlation with estrogen and progesterone receptors while not statistically significant with age and histological types of tumors.
\end{abstract}

Keywords: Breast carcinomas, immunohistochemistry (IHC), HER2/neu, Fluorescence in situ hybridization (FISH).

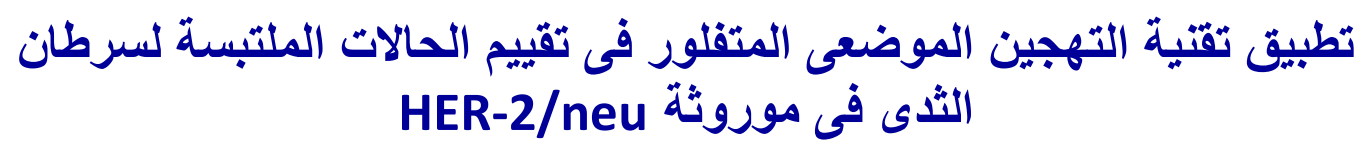

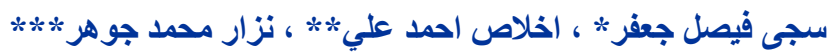

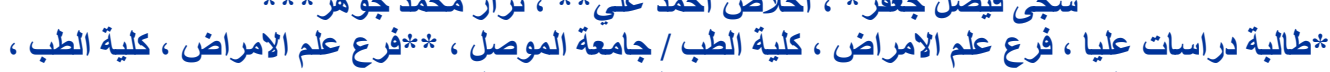

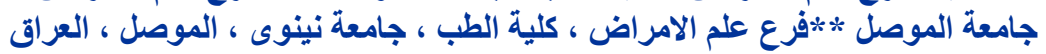


الخلفية: سرطان الثذي هو الورم الخبيث الأكثر شيو عا بين الإناث العر اقيات ويمثل الثالث من السرطانات الإنات المسجلة لإى الإناث.

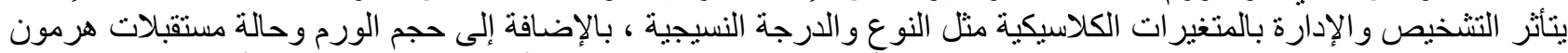

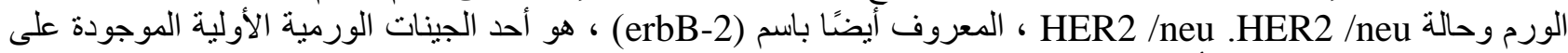

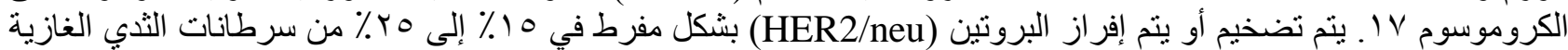
ويرتبط بنتائج سريرية أسو أ. لقد ثبت أن المريضات اللواتي التئ يعانين من سرطان الثذي مع HER2 /neu بحالة موجبة يستجييون

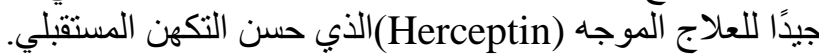

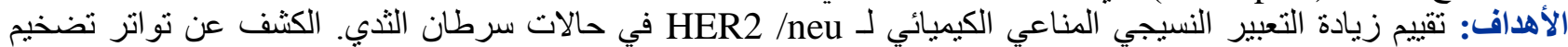
بو بواسطة تقنية التهجين الموضعي المتفلور على الحالات الملتبسة النسيجية المناعية الكيميائية. لربط التعبير المفرط

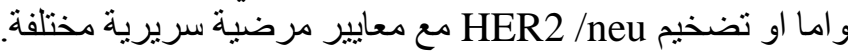

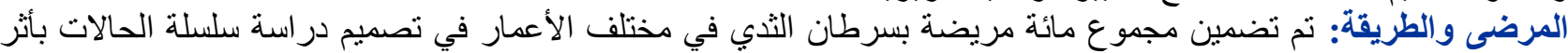

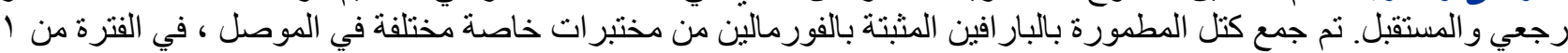

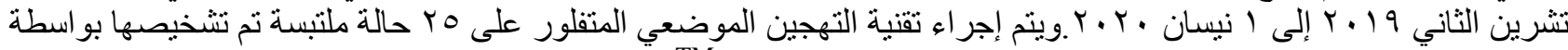

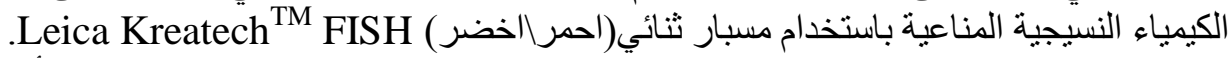

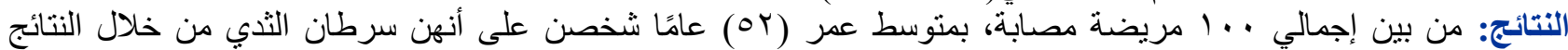

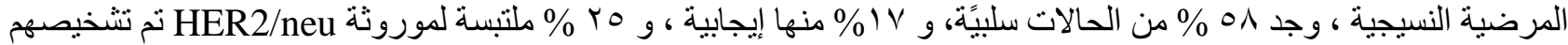

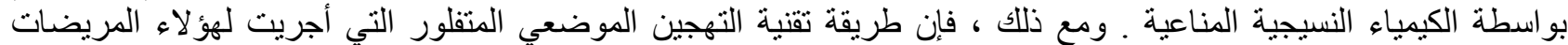

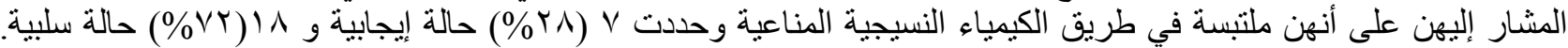

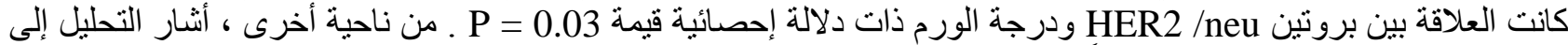

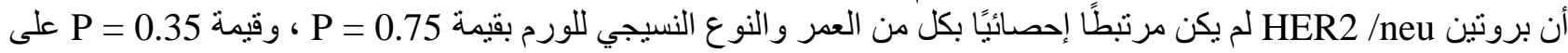

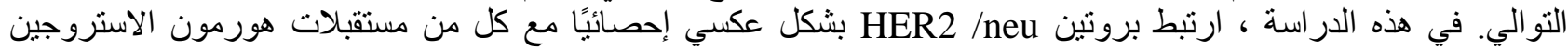

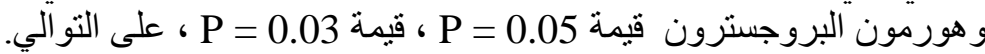

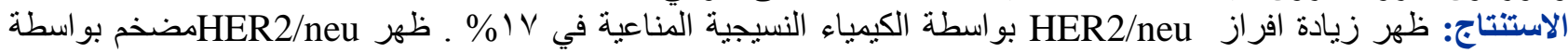

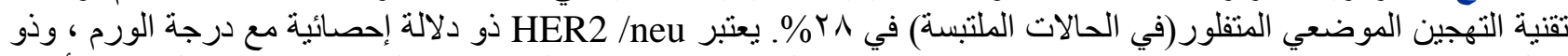

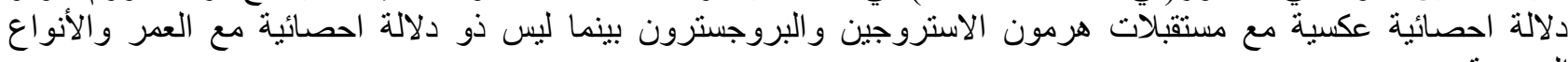

الكلمات المفتاحية: سرطان الثذي ، HER2 /neu ، الكيمياء النسيجية المناعية،تقنية التهجين الموضعي المتفلور.

\section{INTRODUCTION}

uman Epidermal Growth Factor Receptor 2(HER2/neu): HER2/neu (or ErbB-2), is a proto-oncogene encodes $\mathrm{p} 185$, which is a receptor tyrosine-protein kinase involved in many signal transduction pathways, that is located at the long arm of human chromosome 17 (17q12) ${ }^{1,2}$. Recently HER2/neu has become a significant target of therapy for approximately $30 \%$ of breast cancer patients.

In many types of human malignancies HER2/neu has been found to be overexpressed, namely breast, lung cancer, ovarian, prostatic, colorectal, gastric, cancers of the female genital tract and pancreatic. HER2/neu overexpression or amplification in breast cancer is of predictive significance and associated with more aggressive clinical course for the patient. It is related to lymph node metastasis, high tumor-grade, poor response to conventional chemotherapy, decreased survival, high risk of recurrence after surgery ${ }^{2}$ and hormone receptor-negative tumors, although some hormone receptor positive tumors are also HER2/neu positive $\left(\sim 10 \%\right.$ of all invasive breast carcinomas) ${ }^{1}$. It is critically important to identify HER2/neu positive tumors to select patients for HER2targeted therapies, such as trastuzumab as it is expensive and related with cardiac toxicity ${ }^{4}$. Trastuzumab, a humanized monoclonal antibody that connects HER/neu and decreases the risk of recurrence by approximately 50\%, improved overall survival and the results for patients with HER2/neu positive breast cancer ${ }^{5-7}$.

Measuring HER2/neu overexpression and amplification can be done by either immunohistochemistry or florescence in situ hybridization (FISH), respectively and a good relationship exists between these methods. The best approach to HER2/neu testing by many laboratory directors is to start with the immunohistochemical procedure as it is the most frequently used and the proper cost-effective initial test for estimate of HER2/neu protein overexpression. According to the American Society of Clinical Oncology/ College of American 
pathologists (ASCO/CAP) guideline, HER2/neu immunohistochemistry results are generally divided to four scale scores (range, 0 to $3+$ ). The United States Food and Drug Administration(US/FDA) recommends that HER2/neu immunohistochemistry scores of 0 and $1+$ considered as HER2/neu negative, (2+) as HER2/neu equivocal and (3+)scores regarded as HER2/neu positive. If the results are either $0 / 1+$ or $3+$, the test can safely be ended, since the connection with gene amplification or lack of it, respectively, by taking performance of $\mathrm{FISH}$, is nearly $100 \%$. In the event of an equivocal immunohistochemistry result, FISH is recommended ${ }^{1-3}$.

FISH test can be used to visualize portions of genes or specific genes. FISH is well done on tissue that has been kept in chemicals or wax for long time, rather than on fresh or frozen tissue and have been successfully approved for fine needle aspiration biopsy. FISH is considered more accurate and the current gold standard in detecting HER2/neu amplification to avoid erroneous prognostication and inappropriate management. FISH is a practically objective and quantitative method in detecting HER2/neu gene amplification on the nuclei of tumor cells. FISH results are usually available within a few days. Disadvantages of this procedure are complexity, its high costs (10 times that of immunohistochemistry), the temporary signal (it requires a special camera) and the need for a fluorescence microscope ${ }^{8-10}$.

\section{Aim of Study}

1. To assess immunohistochemical overexpression of HER2/neu in breast carcinoma cases.

2. To detect the frequency of amplified HER2/neu by FISH on immunohistochemically equivocal cases.

3. To correlate overexpression and amplification of HER2/neu with various clinicopathological parameters.

\section{MATERIALS AND METHODS Study Design and Patients}

A total of hundred mastectomized breast carcinoma patients at different ages were included in this retrospective and prospective case series study design. Formalin fixed paraffin embedded blocks were selected of histopathologically confirmed carcinoma, collected from different private labs in Mosul between 1st November 2019 to 1 st April 2020.

After preparing slides from blocks, immunohistochemical staining was done for $E R$, $\mathrm{PR}$ and HER2/neu by standard procedure (the antibodies, buffers and glass slides from DAKO ${ }^{\mathrm{TM}}$ (Dako, Denmark)).

Fluorescence in situ hybridization (FISH): In this study, FISH method was performed on only 25 HER2/neu cases tested equivocal by immunohistochemistry technique:

Mount 4 - $6 \mu \mathrm{m}$ formalin-fixed paraffin-embedded (FFPE) tissue sections, Bake mounted FFPE tissue sections for 2 hours at $80^{\circ} \mathrm{C}$, then deparaffinize slides in xylene, incubate for two times 10 minutes at room temperature (RT). Re-hydrate slides in $100 \%, 85 \%$ and $70 \%$ ethanol, incubate for 3 min each at RT. Place slides in deionized $\mathrm{H} 2 \mathrm{O}$ (dH2O), incubate for $3 \mathrm{~min}$ at RT. Place slides in $0.01 \mathrm{M}$ sodium citrate $\mathrm{pH} 6.0$ at $96-98{ }^{\circ} \mathrm{C}$, incubate for $15 \mathrm{~min}$. Place slides in $\mathrm{dH} 2 \mathrm{O}$, incubate for 2 min at RT. Add pepsin to pre-warmed $0.01 \mathrm{M}$ $\mathrm{HCl}$ to reach a final concentration of $0.025 \%$. Digest slides in $0.025 \%$ pepsin in $0.01 \mathrm{M} \mathrm{HCl}$ at $37^{\circ} \mathrm{C}$, incubate for 5 - $45 \mathrm{~min}$. Place slides in $\mathrm{dH} 2 \mathrm{O}$, incubate for $1 \mathrm{~min}$ at RT. Dehydrate slides in $70 \%, 85 \%$, and $100 \%$ ethanol, incubate for 1 min each at RT. Air-dry at RT. Briefly spin down probe vial, vortex probe vial and briefly spin down again before use. Allow Kreatech ${ }^{\mathrm{TM}}$ FISH probes to reach $\mathrm{RT}$ before use, then Co-denaturation done by Applying $10 \mu \mathrm{l}$ of probe per $22 \times 22 \mathrm{~mm}$ field coverslip. Cover with glass coverslip and seal with rubber cement. Denature slide and probe on a ThermoBrite for $5 \mathrm{~min}$ at $80{ }^{\circ} \mathrm{C}$. Hybridization done by Incubation overnight at $37{ }^{\circ} \mathrm{C}$ in a in a ThermoBrite.

Post-hybridization wash by pre-warming Wash Buffer I (0.4 x SSC / $0.3 \%$ Igepal) to $72{ }^{\circ} \mathrm{C}$. Remove rubber cement. Place up to 14 slides in $200 \mathrm{ml}$ of Wash Buffer II (2 x SSC $/ 0.1 \%$ Igepal), incubate for $2 \mathrm{~min}$ at RT, Slide off coverslips. Place up to 14 slides in $200 \mathrm{ml}$ of pre-warmed Wash Buffer I (0.4x SSC / 0.3\% Igepal), incubate for 2 min at $72{ }^{\circ} \mathrm{C}\left( \pm 1^{\circ} \mathrm{C}\right)$ without agitation. Place up to 14 slides in $200 \mathrm{ml}$ of fresh Wash Buffer II (2x $\mathrm{SSC} / 0.1 \%$ lgepal), incubate for $1 \mathrm{~min}$ at RT without agitation. Dehydrate in fresh $70 \%, 85 \%$ and $100 \%$ ethanol, incubate for 1 min each at RT. Air-dry at RT and proceed to Counterstaining: Apply $15 \mu \mathrm{l}$ DAPI counterstain $(0.1 \mu \mathrm{g} / \mathrm{ml})$ and apply glass coverslip. Place slides in the dark and allow $10-15$ min for counterstain to develop then mount using fluorescence microscope.

In at least 200 cells, Signals were counted for both the HER-2/neu gene (red signals) and chromosome 17 centromere signals (green signals) by using Triple band-pass filters (DAPI/FITC/Cy3) to view multiple colors (at x 1000 magnification). Results were expressed as the ratio of Red/green signals (i.e., HER2/CEP17 ratio). Ratio of $<2$ scored as no gene amplification 
(negative), whereas Ratio of $\geq 2$ scored as gene amplification (positive).

Tissue sections mounted can be held for up to 12 months at $2-8{ }^{\circ} \mathrm{C}$ before staining while stained sections should be stored at $-20^{\circ} \mathrm{C}$ to preserve florescent signal and prevent fading and allow stored slides to reach room temperature prior to reading.

\section{Statistical Analysis}

The relationship between HER2/neu positivity (expression and amplification) and the pathological variables were analyzed using Chi-square test and Fisher exact, when necessary. In the analyses, variables with a value of $P \leq 0.05$ were considered statistically significant.

\section{RESULTS}

In this study, mean age of patients was (52) year-old $(\min =31$, $\max =80)$, and the majority of cases mostly seen in $5^{\text {th }}$ and $6^{\text {th }}$ decades $(32 \%$, $33 \%$ ), respectively (Table 1 ).

For histological type, eighty one (81\%) cases were invasive ductal carcinoma- not otherwise specified (IDC-NOS), 16 cases were invasive lobular carcinoma, 2 cases mucinous carcinoma, and 1 case medullary carcinoma (Table 2).

Concerning grading of the tumor, 5 cases $(5 \%)$ well differentiated: $4.2 \%$ of which were positive HER2/neu, 37cases moderately differentiated: $16.6 \%$ of which were positive HER2/neu and 58 cases poorly differentiated: $79.2 \%$ of which were positive HER2/neu (Table 2).

Immunohistochemical study of hormone receptors revealed: 70 cases were ER positive and 30 cases were ER negative while 64 cases were PR positive and 36 cases were PR negative(Table 3).

Immunohistochemical study of HER2/neu revealed: among a total of 100 patients diagnosed as breast carcinoma via histopathological findings, $58(58 \%)$ patients were tested negative, 25(25\%) patients were equivocal and $17(17 \%)$ patients positive for HER2/neu by immunohistochemistry (Figure 1). However, FISH method conducted for those patients indicated as equivocal HER2/neu at immunohistochemistry and identified $7(28 \%)$ cases positive and $18(72 \%)$ negative cases (Figure 2). Therefore, a total of 24 (24\%) patients were considered as positive and 76 (76\%) were negative for HER2/neu (Figure 3 ).

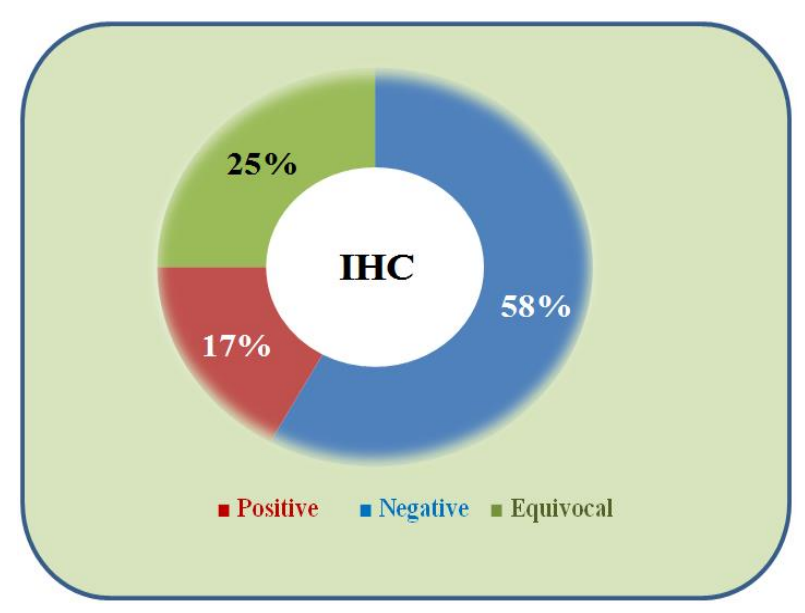

Figure 1. Immunohistochemical overexpression of HER2/neu.

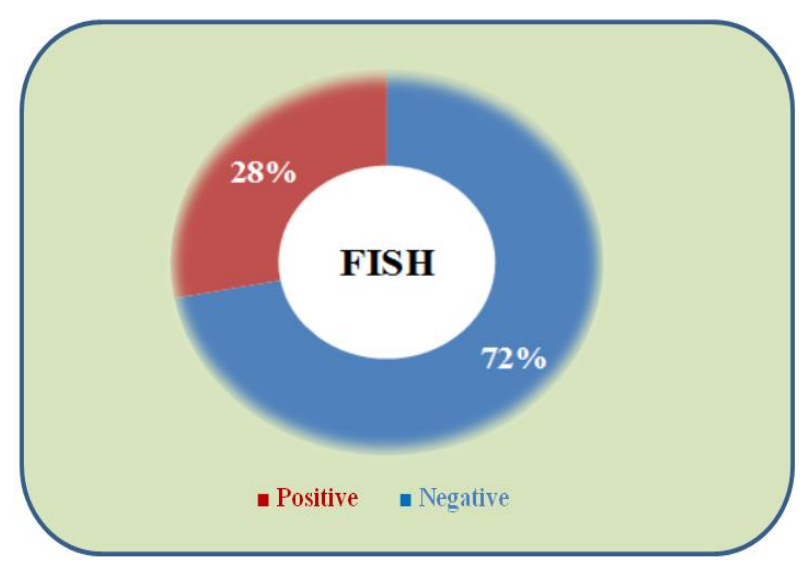

Figure 2. Amplification of HER2/neu by FISH for 25 patients with equivocal immunohistochemistry.

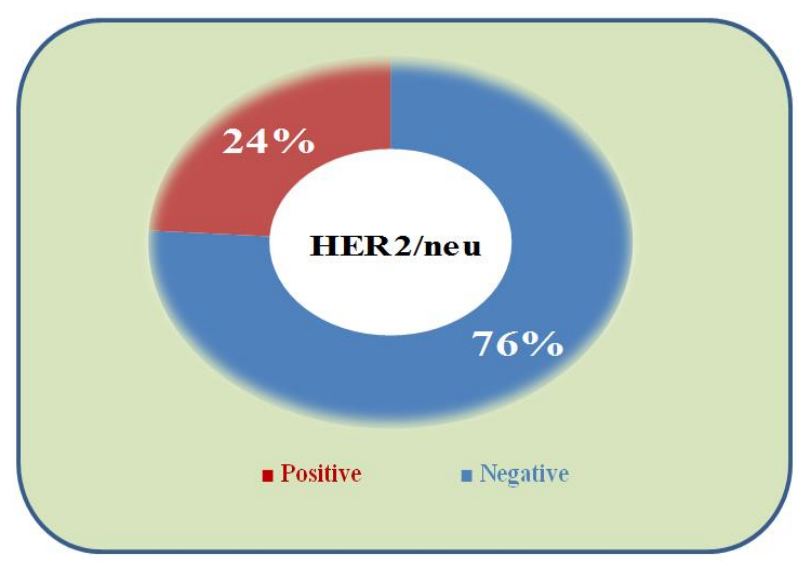

Figure 3. Total HER2/neu results by combined immunohistochemistry and FISH. 
The analysis indicated that HER2/neu did not statistically associated with the age of patients, $P$ value $=0.75$ (Table 1). Also HER2/neu was not statistically associated with histological type of the tumor $P$ value $=0.35$ (Table 2).

While the association between HER2/neu and the grade of the tumor was statistically significant $P$ value $=0.03$ (Table 2 ).

Concerning hormone receptors, HER2/neu was in inverse relation with both ER and PR receptors that is mean high HER2/neu positivity associated with decreased hormone receptor positivity and this relation was statistically significant $P$ value $=0.05, P$ value $=0.03$, respectively $($ Table 3 ).

Table 1. Association between HER2/neu with the age.

\begin{tabular}{|c|c|c|c|c|c|c|}
\hline \multirow{3}{*}{$\begin{array}{l}\text { Age } \\
\text { (year- } \\
\text { old) }\end{array}$} & \multirow[t]{3}{*}{$\mathbf{N}$} & \multicolumn{4}{|c|}{ HER2/neu } & \multirow{3}{*}{$\begin{array}{c}P- \\
\text { value }=\end{array}$} \\
\hline & & \multicolumn{2}{|c|}{$\begin{array}{l}\text { Positive } \\
(n=24)\end{array}$} & \multicolumn{2}{|c|}{$\begin{array}{l}\text { Negative } \\
(n=76)\end{array}$} & \\
\hline & & $\begin{array}{l}n \\
\end{array}$ & $\%$ & $\mathbf{N}$ & $\%$ & \\
\hline $\begin{array}{ll}31 & - \\
40 & \end{array}$ & 14 & 5 & 20.8 & 9 & 11.8 & \multirow[t]{6}{*}{0.75} \\
\hline $\begin{array}{ll}41 & - \\
50 & \end{array}$ & 32 & 8 & 33.3 & 24 & 31.6 & \\
\hline $\begin{array}{ll}51 & - \\
60 & \end{array}$ & 33 & 8 & 33.3 & 25 & 32.8 & \\
\hline $\begin{array}{ll}61 & - \\
70 & \end{array}$ & 13 & 2 & 8.4 & 11 & 14.5 & \\
\hline $\begin{array}{ll}71 & - \\
80 & \end{array}$ & 8 & 1 & 4.2 & 7 & 9.3 & \\
\hline Total & 100 & 24 & 100 & 76 & 100 & \\
\hline
\end{tabular}

Table 2. Association between HER2/neu with the tumor type and grade.

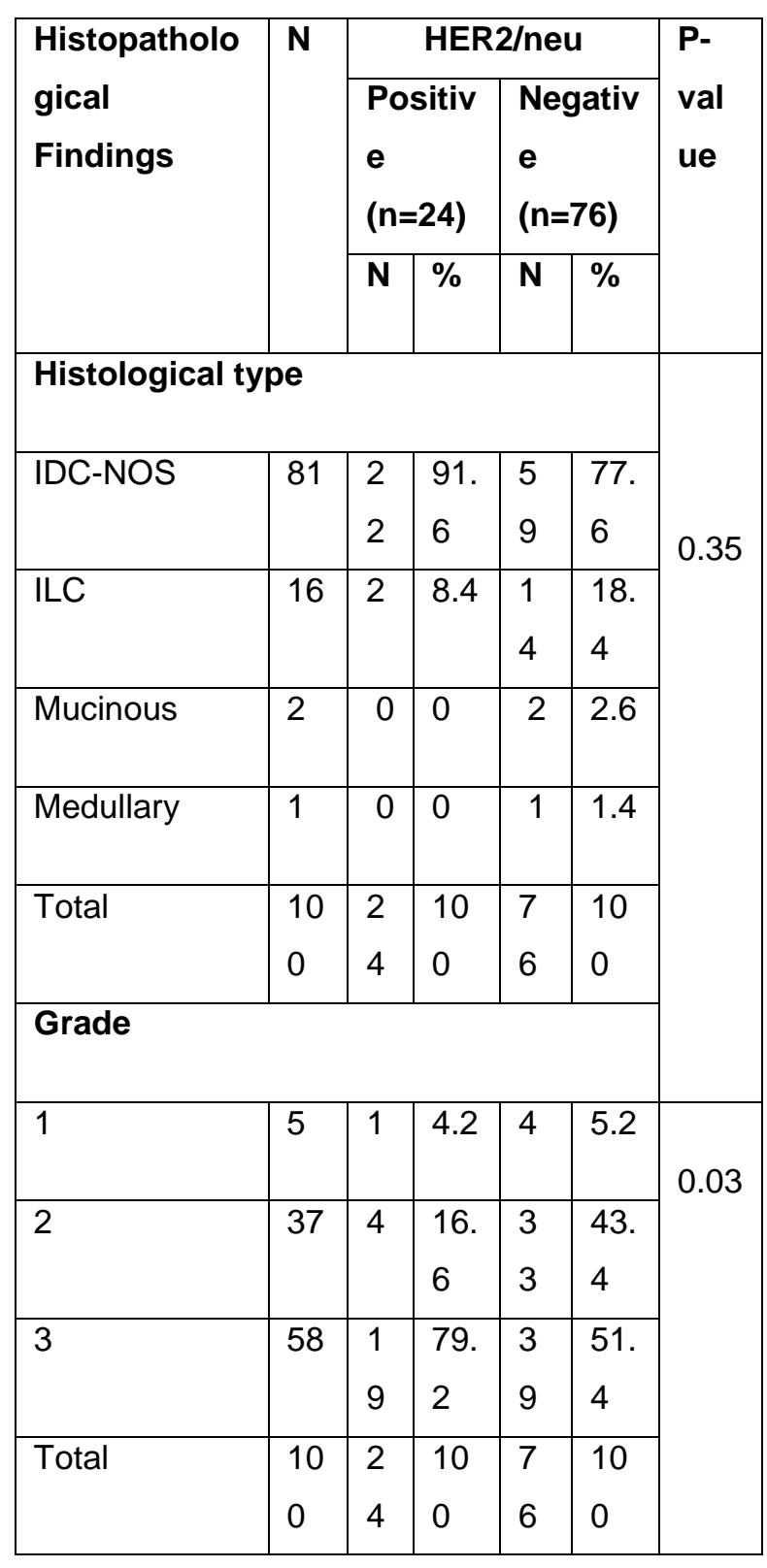

IDC=Invasive Ductal Carcinoma, ILC=Invasive Lobular Carcinoma. 
Table 3. Association between HER2/neu and the hormone receptor status.

\begin{tabular}{|c|c|c|c|c|c|c|}
\hline \multirow{3}{*}{$\begin{array}{c}\text { Hormone } \\
\text { Receptor } \\
\text { s }\end{array}$} & \multirow[t]{3}{*}{$\mathbf{N}$} & \multicolumn{4}{|c|}{ HER2/neu } & \multirow{3}{*}{$\begin{array}{c}\text { P- } \\
\text { valu } \\
\text { e }\end{array}$} \\
\hline & & \multicolumn{2}{|c|}{$\begin{array}{l}\text { Positive } \\
(n=24)\end{array}$} & \multicolumn{2}{|c|}{$\begin{array}{l}\text { Negativ } \\
\text { e }(n=76)\end{array}$} & \\
\hline & & $\mathbf{n}$ & $\%$ & n & $\%$ & \\
\hline \multicolumn{6}{|c|}{ Estrogen (ER) } & \multirow{4}{*}{0.05} \\
\hline Positive & 70 & 1 & $\begin{array}{l}54 . \\
2\end{array}$ & 5 & 75 & \\
\hline Negative & 30 & 1 & $\begin{array}{l}45 . \\
8\end{array}$ & 1 & 25 & \\
\hline Total & $\begin{array}{l}10 \\
0\end{array}$ & 4 & 100 & 6 & 100 & \\
\hline \multicolumn{6}{|c|}{ Progesterone (PR) } & \multirow{4}{*}{0.03} \\
\hline Positive & 64 & 1 & $\begin{array}{l}45 . \\
8\end{array}$ & 5 & $\begin{array}{l}69 . \\
7\end{array}$ & \\
\hline Negative & 36 & 1 & $\begin{array}{l}54 . \\
2\end{array}$ & 2 & $\begin{array}{l}30 . \\
3\end{array}$ & \\
\hline Total & $\begin{array}{l}10 \\
0\end{array}$ & 2 & 100 & 7 & 100 & \\
\hline
\end{tabular}

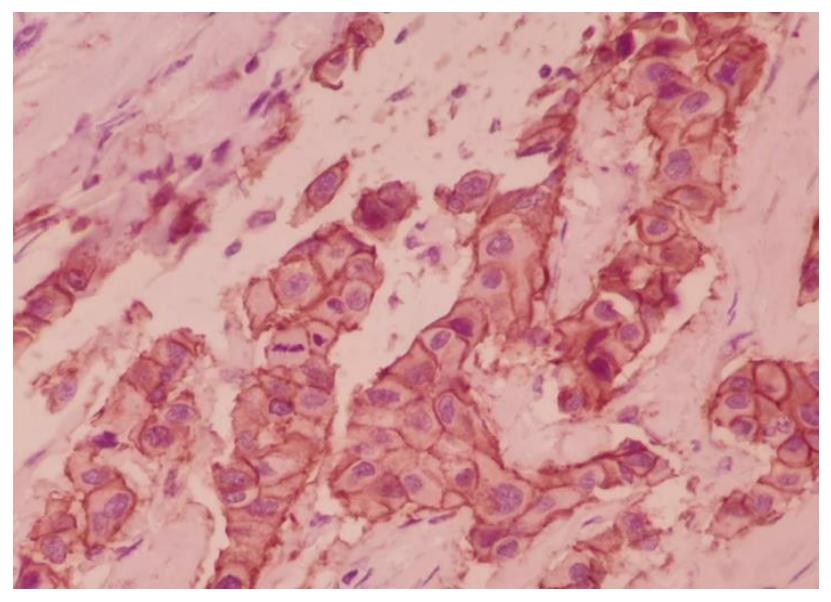

Figure 4: Immunohistochemistry of HER2/neu Equivocal (+2).

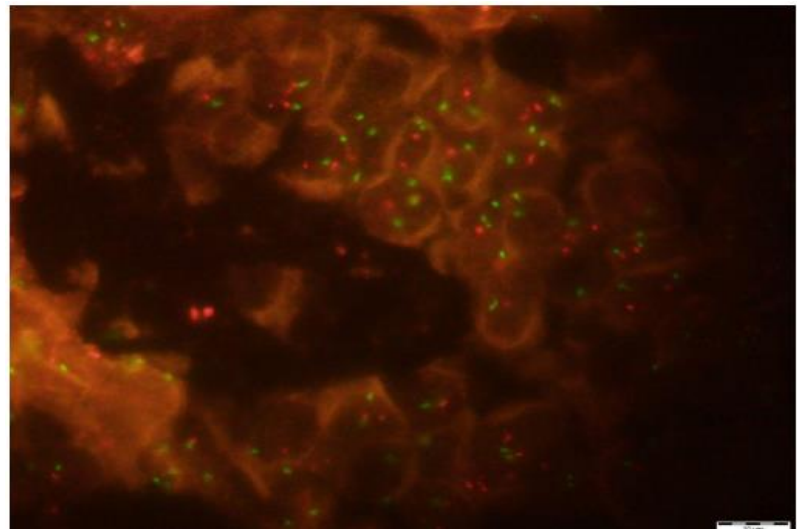

Figure 5: FISH of HER2/neu in breast carcinoma .There is no amplification of HER2/neu. Presence of an average of two red and two green signals per nucleus (less than 1.8).

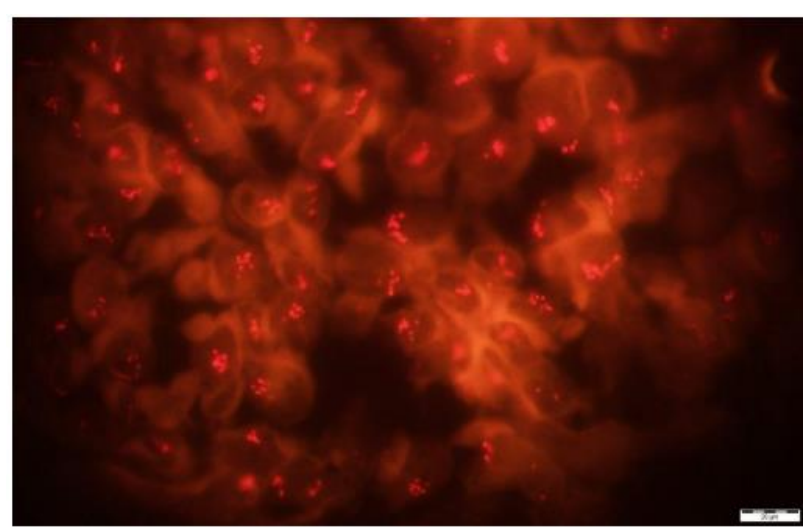

Figure 6: FISH of HER2/neu in breast carcinoma with high level of amplified HER2/neu. Presence of numerous red signals arranged in clusters (more than 2.2).

\section{DISCUSSION}

In pathological reports of invasive breast carcinoma, evaluation of HER2/neu status has become part of the core dataset in the accurate reporting which is an important for the correct ${ }_{10}$ selection of patients for specific targeted therapy.

Some evidence for the therapeutically significant HER2/neu predicts that FISH testing to be more accurate, although that the main immunohistochemistry screening supplemented by molecular FISH is widely used approach. However, many centers in invasive breast cancer cases suggested the foremost evaluation by immunohistochemistry followed by FISH in equivocal immunohistochemistry results ${ }^{10}$.

In the current study, the percentage of equivocal cases of HER2/neu was higher than that reported by Caldarola et al $(13 \%)^{3}$, Garrison et al $(12 \%)^{11}$, and Ogoura et al $(9 \%)^{12}$, in contrast to Goud et al 
$(31 \%)^{2}$. A potential reason of having higher percentage of equivocal in the current study could be due to variations in processing conditions, fixation time and fixative type that can lead to diversity in the intensity of staining especially with the use of heat activation epitope retrieval that lead in a shift towards "false" positive staining (a positive result on immunohistochemistry in the absence of gene amplification) ${ }^{10}$.

FISH results in this study on equivocal cases were revealed $72 \%$ non-amplified HER2/neu and $28 \%$ were amplified. The result of this study is in line with what has been found by Musa et al (65.4\%negative, $34.6 \%$ Positive) ${ }^{8}$; Payandeh et al (67.6\% negative, $32.4 \%$ Positive) ${ }^{13}$ and Lee et al (86\% negative, $14 \%$ Positive) ${ }^{14}$.

Association of HER2/neu status to some Clinicopathological Parameters: In present study HER2/neu amplification is not significantly associated with age. HER2/neu positivity occur in different age groups but mostly in $5^{\text {th }}$ and $6^{\text {th }}$ decades, our explanation may be due to consanguineous marriages (hereditary factor play a central role), so age require further careful studies to know the nature of it or may be due to obesity due to lack of exercise and bad habit diet (high fat, protein and high carbohydrate). Results in present study is in line with results of other literatures. Salmon et $\mathrm{al}^{5}$; Musa et $\mathrm{al}^{8}$; Ayadi et al ${ }^{15}$; Metib et al ${ }^{16}$ and Wang et al ${ }^{17}$. While Ortiz et al ${ }^{18}$ found significant association of HER2/neu positivity to age.

Concerning histological type, it is not significantly associated with HER2/neu positivity, although only 2 cases of lobular carcinoma were positive and the remaining 22 were invasive ductal carcinoma, the reason may be due to that lobular carcinoma is equally aggressive or due to this survey was limited to small number of non-ductal subtypes ${ }^{15}$. Wang et al ${ }^{17}$ and Ayadi et al ${ }^{15}$ also found no association.

Concerning grade, in present study there was a significant relation between grade of tumor and HER2/neu positivity. The reason for that, HER2/neu is related to cell growth and proliferation thus it is mostly concerned with high grade tumors 1 . Goud et $\mathrm{al}^{2}$ and Ayadi et al ${ }^{15}$ found similar results to this study.

Immunohistochemical study of hormone receptors has revealed that HER2/neu positivity were in inverse relationship with hormone receptors. This could be due to complex interactive signaling between ER and other growth factor signaling pathways ${ }^{2}$.

Thirteen cases were positive for HER2/neu and ER, HER2/neu amplification in these tumors is reported to be related to resistance to tamoxifen therapy. It is supposed that in these tumors, tamoxifen functions as an estrogen agonist to enhance growth in breast cancer cells, which express high levels of HER2/neu and estrogen receptor co-activation resulting in de novo resistance for tamoxifen ${ }^{10}$.

As for hormone receptors, many literatures like Goud et $\mathrm{al}^{2}$; Salmon et al ${ }^{5}$; Musa et al ${ }^{8}$; Ayadi et $\mathrm{al}^{15}$ and Panjwani et al ${ }^{19}$ also had similar finding to these results, an inverse relationship between hormone receptors and HER2/neu positivity .

\section{CONCLUSION}

HER2/neu is overexpressed by Immunohistochemistry in $17 \%$. HER2/neu is amplified by FISH (in equivocal cases) in $28 \%$. HER2/neu is statistically significant with tumor grade, estrogen and progesterone receptors while not statistically significant with age and histological tumor types.

\section{REFERENCES}

1. Goldblum J R, Lamps L. W., McKenny J. K., Myers J L. Breast: chapter 36. In: Rosai and Ackerman's Surgical Pathology, edition; 2018.

2. Goud KI, Dayakar S, Vijayalaxmi K, Babu SJ, Reddy PV. Evaluation of HER-2/neu status in breast cancer specimens using immunohistochemistry (IHC) \& fluorescence insitu hybridization (FISH) assay. The Indian Journal of Medical Research. 2012; 135:312-7.

3. Caldarola L., Petroni S, Scamarcio R. FISH testing of HER2 immunohistochemistry 1+ invasive breast cancer with unfavorable characteristics. Oncol Lett. 2016 .Nov; 12(5): 3115-22.

4. Telli ML, Hunt SA, Carlson RW, Guardino AE. Trastuzumab-related cardiotoxicity: calling into question the concept of reversibility. Journal of Clinical Oncology. 2007; 25 (23): 3525-33. doi:10.1200/JCO.2007.11.0106. PMID 17687157.

5.Slamon DJ, Clark GM, Wong SG, Levin WJ, Ullrich A, McGuire WL. Human breast cancer: Correlation of relapse and survival with amplification of the HER-2/neu oncogene. Science. 1987; 235:177-82. doi: 10.1126/science.3798106.

6. Dendukuri N, Khetani K, Mclsaac M, Brophy J. Testing for HER2-positive breast cancer: A systematic review and cost-effectiveness analysis. CMAJ. 2007; 176:1429-34. doi: 10.1503/cmaj.061011. 
7. Yarden Y. Biology of HER2 and its importance in breast cancer. Oncology. 2001; 61(Suppl2): S1S13. doi: $10.1159 / 000055396$.

8. Musa Z, Qasim B, Al Shaikhly AW. Evaluation of Immunohistochemistry-Equivocal (2+) HER2 Gene Status in Invasive Breast Cancer by Silver DNA in Situ Hybridization (SISH) and its Association with Clinicopathological Variables. Iranian Journal of Pathology. 2017; 12(1):9-19.

9. Carlson, B. HER2 tests: How do we choose? Biotechnol Healthc. 2008 Sep-Oct; 5(3): 2327.PMC2706184.

10. Mostafa N, Eissa S. , Belal D., Shoman S. H. Assessment of Her-2/neu gene amplification status in breast carcinoma with equivocal 2+ Her-2/neu immunostaining. Journal of the Egyptian National Cancer Institute. 2011 March. 23 (1), 41-46. doi:10.1016/j.jnci. 07.006

11. Garrison LP, Lalla $D$, Brammer $M$, Babigumira JB, Wang B, Perez EA. Assessing the potential cost-effectiveness of retesting $\mathrm{IHCO}, \mathrm{IHC1+}$, or FISH-negative early stage breast cancer patients for HER2 status. Cancer. 2013; 119:3113-22. doi: 10.1002/cncr.28196.

12. Ogura $H$, Akiyama $F$, Kasumi $F$, Kazui $T$, Sakamoto G. Evaluation of HER-2 status in breast carcinoma by fluorescence in situ hybridization and immunohistochemistry. Breast Cancer. 2003; 10:234-40.

13. Payandeh $M$, Sadeghi $M$, Sadeghi E, Koohian AK. Comparison of IHC, FISH, ER and PR in breast cancer in Western Iran. Am J Cancer Prevent. 2014; 2: 37-41.

14. Lee AH, Key HP, Bell JA, Hodi Z, Ellis IO. Breast carcinomas with borderline (2+) HER2 immunohistochemistry: percentage of cells with complete membrane staining for HER2 and the frequency of HER2 amplification. J Clin Pathol 2011;64:490.

15. Ayadi L, Khabir A, Amour H, Karray S, Dammak A, Guermazi M, et al. Correlation of HER-2 over-expression with clinico-pathological parameters in Tunisian breast carcinoma. Tunisia. 2008; 6:11

16. Metib $\mathrm{N}$ J., Jebur $\mathrm{H}$ K, Hamzah K. S. Correlation and frequency of HER-2/neu Status With Estrogen and Progesterone Receptors in Breast Carcinomas: Karbala Journal of Medicine 2016; Volume 9, Issue 2, Pages 2588-99.

17. Wang L, Wang X, Nie X, Ma L. Comparison of fluorescence in situ hybridization and immunohistochemistry for assessment of Her-2 status in breast cancer patients. J Huazhong Univ Sci Technolog Med Sci. 2009; 29(3):3548.

18. Ortiz AP, Frías $O$, González-Keelan $C$, Suárez E, Capó D, Pérez J, et al. Clinicopathological factors associated to HER-2 status in a hospital- based sample of breast cancer patients in Puerto Rico. Puerto Rico Health Sciences Journal 2010; 29(3):265-71.

19. Panjwani $P$, Epari $S$, Karpate $A$, Shirsat $H$, Rajsekharan P, Basak R, et al. Assessment of Her-2/neu status in breast cancer using fluorescence in situ hybridization and immunohistochemistry. Indian J Med Res 2010;132:287-94. 